\title{
Azul ou rosa: manifestações identitárias de gênero sob o viés normativo do consumo ${ }^{1}$
}

\section{Resumo}

Pensar no consumo como força que influencia identidades é assumir a importância das peças e campanhas publicitárias na formação dos sujeitos sociais. Com o desejo de pensar algumas questões acerca das identidades de gênero relacionadas ao consumo, foi realizada a análise de imagens que tratam destas temáticas. A partir deste percurso, foi possível perceber que existe uma força no sentido normativo, ou seja, que coloca o sujeito adequado a determinados padrões identitários. O consumo passa a desempenhar, portanto, importante papel na construção do contexto normativo das identidades de gênero. A pesquisa foi desenvolvida a partir de um método teórico analítico e com o objetivo de reconhecer o consumo como tecnologia social de normatização das identidades de gênero.

Palavras-chave: Consumo; Comunicação; Gêneros; Normatização.

\author{
Daniel Keller \\ Mestrando em Processos e \\ Manifestações Culturais na \\ Universidade Feevale; Bolsista \\ FAPERGS - RS. \\ Brasil \\ danielgkeller@gmail.com
}

Denise Castilhos de Araujo

Doutora em Comunicação Social;

Professora do Mestrado em

Processos e Manifestações

Culturais da Univ. Feevale - RS.

Brasil

deniseca@feevale.br

\section{Para citar este artigo:}

KELLER, Daniel; ARAUJO, Denise Castilhos de. Azul ou rosa: manifestações identitárias de gênero sob o viés normativo do consumo. Revista PerCursos. Florianópolis, v. 16, n.30, p. 221 - 235. jan./abr. 2015.

\section{DOI: $10.5965 / 1984724616302015221$}

http://dx.doi.org/10.5965/1984724616302015221

\footnotetext{
${ }^{1}$ Projeto de pesquisa em Estudos da Cultura e Memória da Comunidade, linha de pesquisa Memória e Identidade, com apoio da Fundação de Amparo à Pesquisa no Estado do Rio Grande do Sul - FAPERGS.
} 


\title{
Pink or Blue: Identity Gender Manifestations under the bias of normative consumption
}

\begin{abstract}
The ideia of consumption as a force that influences identities is fundamental to assume the importance of advertising campaigns in the formation of social subjects. The desire to think some questions about the gender identities related to consumption lead the analysis of images that deal with these issues. In this analysis, it was revealed that there is a force in the normative sense, which puts the proper subject to certain selfhood. Therefore, consumption comes to play important role in building the normative context of gender identities. The research was developed from an analytical and theoretical method with the objective of recognizing consumption as social technology standardization of gender identities.
\end{abstract}

Keywords: Consumption; Communication; Genres; Standardization. 


\section{Introdução}

O contemporâneo pode ser analisado a partir das implicações da globalização e da liquidez pós-moderna na construção das identidades individuais e coletivas. Assim, se pressupõe que as representações de gênero também são influenciadas por estes vetores, portanto, assumem características singulares com relação à sua manifestação cultural, principalmente, no que se refere às questões normativas. Representações de gênero, neste caso, se referem ao conceito de "representação" proposto por Chartier, uma vez que ela é usada pelo grupo teórico estabelecido para este estudo. Dentro do uso de Butler (2008) a proposta teórica de Chartier prevê que representação é a exibição de um objeto não presente que, por sua vez, é substituído por uma imagem capaz de reconstruílo. Ao mesmo tempo, estabelece uma presença, como uma existência pública de algo ou alguém. Ainda sobre representações identitárias de gênero, Butler (2008) apresenta um conceito que pressupõe normatividades textuais aplicadas aos sujeitos, mas este conceito mais específico não será abordado nesta etapa do trabalho. Esta normatividade, por sua vez, também é estabelecida pelas políticas do consumo que desenvolvem significativa importância dentro do contexto histórico atual.

Este trabalho, que se trata de um espaço para refletir sobre determinadas questões relacionadas às identidades de gênero, dedica-se a analisar de que forma o gênero se manifesta na cultura, como influencia a construção identitária dos sujeitos e de que forma o consumo funciona como tecnologia social de normatização. Para tanto, percebe-se como fundamental estudar as relações entre gênero, identidade e cultura; analisar situações contemporâneas em que o consumo se torna regulador e, portanto, cria estereótipos e marginalizações aplicados ao gênero. Por fim, busca entender de quais formas a alteridade ajudaria a quebrar estas fronteiras normativas, expandido as possibilidades de vivência do gênero no contemporâneo.

Para que esta quebra normativa possa acontecer, é preciso, primeiramente, desmistificar as relações entre corpo e gênero e reforçar a visão de gênero como constituinte da identidade - com características mutáveis e definidas socialmente. Em 
seguida, tornar visíveis as práticas reguladoras do consumo, como forma de apelo às necessidades de libertação.

Assim, através de uma pesquisa bibliográfica e documental, com objetivo descritivo, este trabalho parte da seguinte problemática: como se manifestam as identidades de gênero na cultura e de que forma o consumo normatiza estas manifestações?

As identidades influenciadas pelas normatizações do consumo passam a ter seus hábitos influenciados pelas coerções sociais que, têm como consequência, práticas inclusive de gênero - totalmente restritas ao que o modelo hegemônico estabeleceu como padrão. No entanto, é fundamental demonstrar de que forma estas identidades se estabelecem e são vivenciadas dentro do contexto pós-moderno.

\section{Identidade e gênero como manifestação cultural}

O contemporâneo é regido por um conjunto de signos que de algum modo intervêm e influenciam a forma com que os sujeitos veem e entendem a realidade. Esta interpretação se constrói a partir de uma rede cultural (GEERTZ, 2003), compreendida de uma leitura dos textos, corpos e representa seus sujeitos através de um código e dentro de um contexto. O jogo simbólico social desenha hierarquias baseadas em dinâmicas de domínio dos grupos hegemônicos (masculino sobre feminino, heterossexual sobre homossexual, padrão sobre marginal), principalmente, influenciadas pelas representações de saber e poder (HALL, 2006).

Diante do sujeito pós-moderno proposto por Hall (2006), percebe-se o contato com diversas possibilidades de identidades singulares. Estes modelos de identidades pósmodernas estão baseados em movimentos de libertação do pré-disposto tradicional e da quebra com "qualquer condição precedente (...), mas caracterizada por um processo sem fim de rupturas e fragmentações internas do seu próprio interior" (David Harvey, 1989, p. 12 apud Hall, 2006). 
O contexto pós-moderno, na abordagem proposta por Hall (2006), é complexo, portanto, composto de inúmeras variáveis correlacionadas entre si, determinando um sujeito fragmentado, preterindo as identidades unificadas e estáveis. A corporalidade existente neste cenário acompanha as mais diversas possibilidades de construção da subjetividade, dentro da celebração móvel.

Aplicando a visão do "eu fragmentado" às identidades, são possíveis inúmeras variáveis para a vivência de "feminino" e "masculino", quebrando padrões de opositivos entre mulheres e homens e estabelecendo possibilidades identitárias intermediárias e transitórias. A existência da liberdade de representação identitária reconhece a necessidade de diferenciação e plenitude da vivência.

Ao contrário do que se entende como processo de construção identitária, dentro do marco social, os gêneros têm sido estabelecidos através de uma relação irredutível, fixa e reguladora que indissocia a identidade sexual do corpo. Da mesma forma, o consumo tem atendido majoritariamente estas pretensões padronizadas e não tem aberto espaço para outras possibilidades menos hegemônicas. Desta forma, são criados paradoxos entre heterossexual/dentro em contraponto com, por exemplo, transexual/fora. Nesta relação, o marco social exclusivamente aceita o que se entende pelo padrão binário, masculino ou feminino, marginalizando todas as outras possibilidades.

Toma-se a visão de construção sexual pelo princípio de Butler(2008, p.153) que é “parte de uma prática regulatória que produz os corpos quegoverna". O "sexo" é, pois, não simplesmente aquilo que alguém tem ou uma descrição estática daquilo que alguém é: ele é uma das normas pelas quais o "alguém” simplesmente se torna viável, é aquilo que qualifica um corpo para a vida no interior do domínio da inteligibilidade cultural (BUTLER, 2008, p.154-155).

Neste sentido, cada representação de gênero e sexualidade precisa ser analisada como única e mutável, adequada à identidade do sujeito pós-moderno proposto por Stuart Hall (2006). Esta rede de relações interconectadas coloca o sujeito como um 
componente influenciado e que influencia a cultura confirmando a abordagem de Geertz (2003).

Considerando estas características dos sujeitos pós-modernos, o papel do consumo passa a ser de criar formas de identificação e completude das identidades sociais. Ambivalente, o consumo tanto confere existência e aceitação, como também marginaliza e exclui (BAUMAN, 1999). Esta característica do consumo, portanto, tem condições de legitimar as normatividades estabelecidas pelo marco social, com forte capacidade de organizar a sociedade em representações padronizadas e hegemônicas.

\section{Consumo normativo e consumo libertário: aplicações sobre identidades de} gênero

A sociedade contemporânea estratifica sujeitos através de diversos mecanismos e tecnologias sociais (FOUCAULT, 1988) de modo a criar certa organização em categorias identitárias. A normatividade estabelece que algumas destas identidades se posicionem dentro de uma significação aceita e outras marginalizadas. Estas fronteiras regulamentadoras constituem práticas sociais de exclusão a partir da adequação ou não ao marco social ou comportamento hegemônico.

Como uma das mais importantes formas de opressão e regulação das construções identitárias, o consumo designa papéis aos sujeitos, de forma a não respeitar a liberdade de opção por determinada representação de gênero - que pode, ou não, estar adequada ao corpo físico. Por exemplo, as sexualidades “trans", tratadas por Judith Butler (1993), quebram as lógicas de pertencimento biológico, participando de uma relação ambígua de dois gêneros, masculino e feminino. Estas identidades extrapolam as possibilidades corporais previstas pelo binarismo opositivo e pouco tem suas necessidades atendidas pelas dinâmicas do consumo.

Materializando a normatividade binária que se refere às práticas de gênero e sexualidade, a artista sul coreana Jeong Me Yoon desenvolveu um trabalho de registro de 
crianças, em seus quartos, rodeadas de uma infinidade de produtos de cor azul ou rosa. Como pode ser visto nas imagens a seguir:

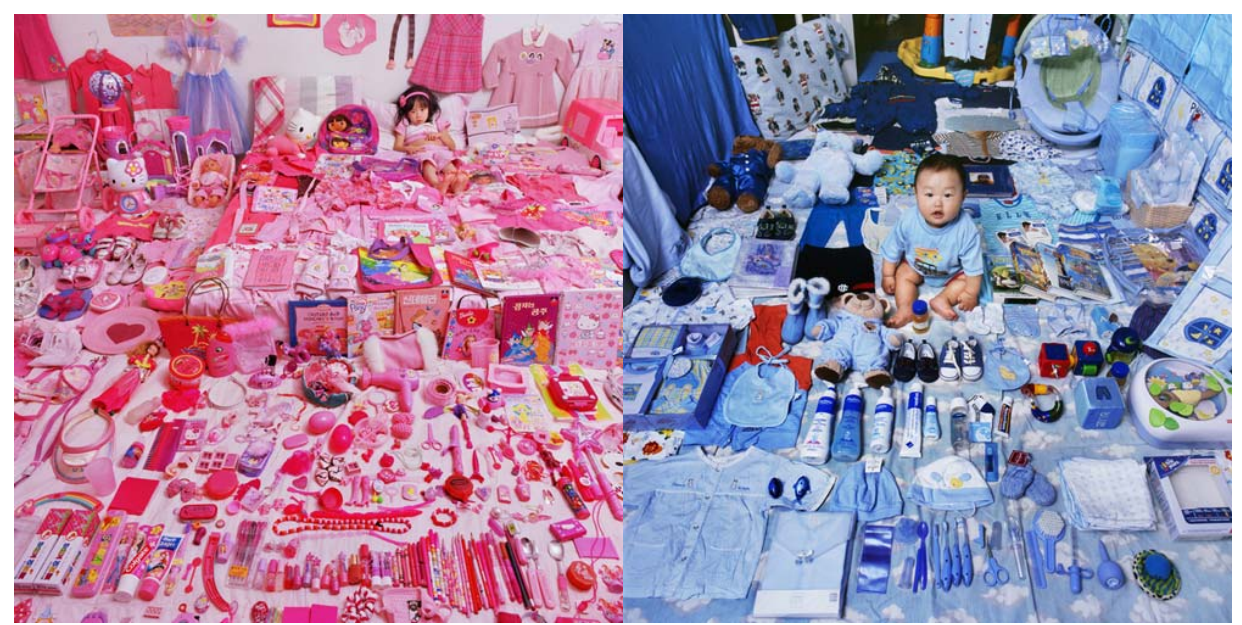

Figura 1 - The Pink and Blue Project - Jeong Me Yoon

Fonte: Site OvoNovo. Acesso em 05 de Agosto de 2014.

Na mostra fotográfica realizada na Coréia, a artista questiona a prática do consumo exacerbado, já nos primeiros anos de vida e demonstra o poder de coerção do consumo no sentido de definir um código de conduta para o corpo entendido como masculino ou como feminino a partir da escolha de cores. A estrutura reguladora do consumo, acaba por estabelecer um modelo de representação para estes sujeitos, demonstrando o aprisionamento desenvolvido por esta tecnologia social, no sentido de fixar identidades (também de gênero), portanto, exclusivamente biológicas, imutáveis e a-históricas - contrariando totalmente a visão de identidade do sujeito pós-moderno proposta por Stuart Hall (2006).

Servindo da proposta teórica apresentada por Bauman (1999), entende-se que não existe uma possibilidade de escolha individual, na sociedade de consumidores "ninguém pode manter segura sua subjetividade sem reanimar, ressuscitar e recarregar de maneira perpétua as capacidades esperadas e exigidas de uma mercadoria vendável" (BAUMAN, 2008, p.22). Esta característica estabelece uma normatividade que se dá através de uma forma de arranjo rotineiro, permanente e adequado ao regime hegemônico, assim 
transformando-se na principal força propulsora e operativa da sociedade, uma força que coordena a reprodução sistêmica, a integração e a estratificação sociais, além da formação de indivíduos humanos, desempenhando ao mesmo tempo um papel importante nos processos de autodefinição individual e de grupo, assim como na seleção e execução de políticas da vida individuais. (BAUMAN, 2008, p. 41)

Para Bauman (2008), no contexto líquido não se pode ser sujeito sem antes virar mercadoria. Este fato tem como consequência uma intrínseca formação estereotipada das representações de gênero, para a qual homens precisam usar a cor azul na infância e quando adultos precisam responder a um conjunto de responsabilidades ditas masculinas, ligadas à autoridade.

Essas operações sistêmicas e estratificadoras não são somente aplicadas aos não aptos ao consumo (que não possuem capacidade de alcance a determinado tipo de compra), mas também definem práticas de exclusividade binária com relação aos gêneros - confirmando que, no contexto normativo, se pertence exclusivamente e eternamente ao masculino ou ao feminino.

A prática é adotada também pela regularidade que promove, no sentido de adequar sujeitos ao marco social, constituindo um cenário cultural neutro e uniforme. $\mathrm{O}$ consumo de objetos das cores rosa ou azul ajuda a constituir uma representação normativa do gênero, pouco importando a função prática do objeto, mas com foco na questão simbólica atrelada à cor. A representação normativa dos gêneros reforça um texto de estratégias metafóricas e metonímicas, deslocado, predeterminado, agressivo e que cria oposições discriminatórias - remetendo às abordagens da construção de estereótipos proposta por Bhabha (1998).

Por esse prisma conceitual, a discriminação e preconceitos aplicados às identidades de gênero não binárias e/ou flexíveis obscurecem as diferenças entre os dois opostos e trabalha em contrapostos que se expressam de modo estereotipado no comportamento, no caráter, no desejo, na subjetividade, na sexualidade, na identificação de gênero e na experiência história (BUTLER, 2008). Esse processo de padronização constituído a partir da oposição binária (masculino versus feminino) ocultaria todas as 
possibilidades que existem ou transitam entre estes dois polos, eliminando qualquer tipo de pluralidade, real ou simbólica.

A não existência de um consumo focado nas identidades de gêneros não binárias (masculina ou feminina) está atrelada aos silêncios articulados que, por sua vez, revelam uma não adequação à ideologia hegemônica. A invisibilidade ou emudecimento das identidades pode ser analisada como uma forma de penalização e que possui como consequência a exclusão (BAUMAN, 2008). A visibilidade de identidades não regulares não se dá no mercado de consumo normativo, pois, da mesma forma que ele categoriza em azul ou rosa, está também excluindo qualquer outra possibilidade que não sejam estas duas, influenciando em seu apreço e estimas sociais.

Contudo, é notável o crescimento de mercados de consumo segmentados em identidades de gênero homossexuais. Este nicho tem se valido de estruturas normativas que também acabam por criar estereótipos tanto de identidades, quanto de gêneros mesmo quando aplicadas às identidades de gênero reconhecidamente marginalizadas como a de gays masculinos.

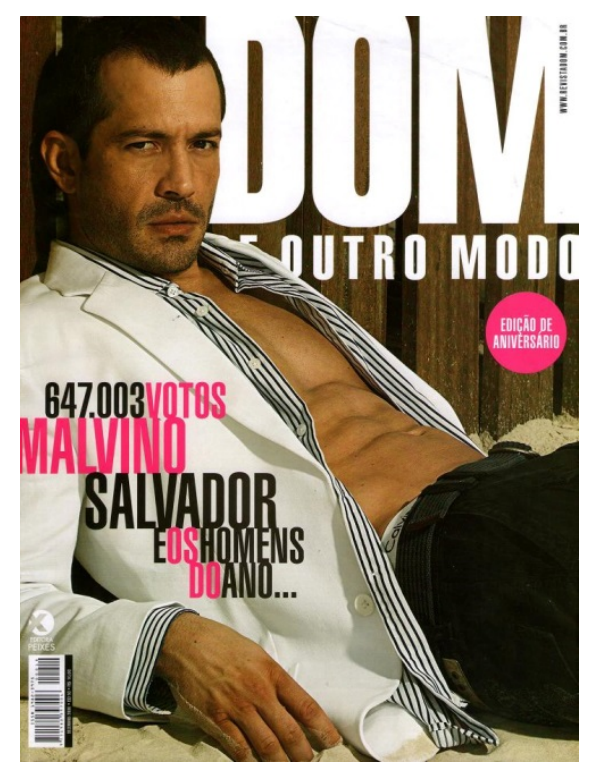

Figura 2 - Primeiro exemplo de capa Revista “Dom” de dezembro de 2008 Fonte: Magazine Obsession, acesso em abril de 2015. 
Na capa da revista brasileira Dom, o personagem em destaque é o ator Malvino Salvador, que costumeiramente interpreta papéis de galã em novelas veiculadas pela rede Globo. É necessário atentar à escolha de um modelo estereotipado e normatizado de corpo - caucasiano, com músculos definidos - que sugere certa valorização às características de masculinidade padrão, conforme foi definido por Bourdieu (2014).

Outro ponto importante que aparece nesta imagem é a relação com o consumo de luxo que é representado pelo uso de peças da indumentária como camisa e blazer. Tradicionais da moda formal, estas peças indicam seu uso em ambientes mais sofisticados - inclusive, pelo uso do blazer branco. Todas estas características sugerem um tipo de capacidade financeira mais elevada ${ }^{2}$.

Estas questões podem ser observadas na capa da mesma revista que traz o modelo Oraine Barrett, como uma forma de contrastar as abordagens através de perspectivas étnicas - apresentada na figura 3.

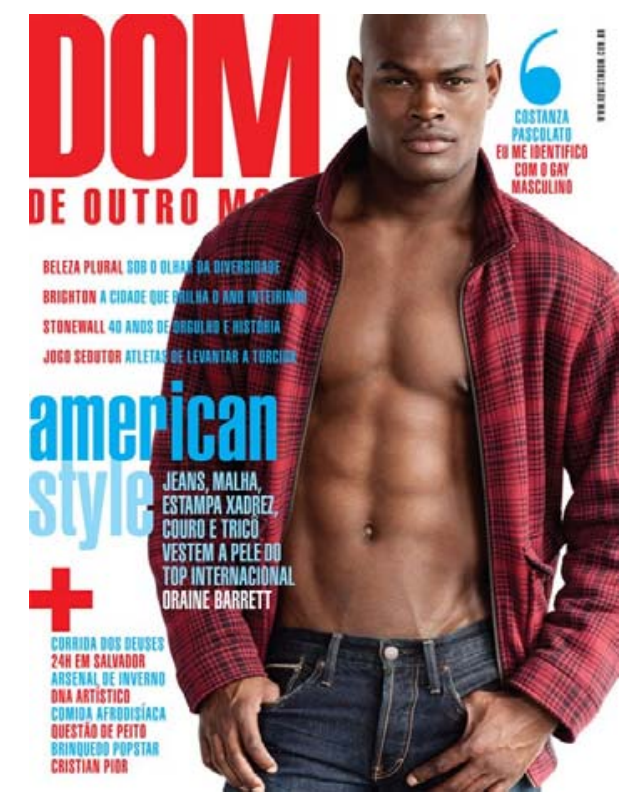

Figura 3 - Segundo exemplo de capa da revista “Dom” de junho de 2009 Fonte: NoiseMaker, acesso em abril de 2015.

\footnotetext{
${ }^{2}$ Os autores já desenvolveram estudos neste sentido publicados em KELLER, Daniel; CASTILHOS, Denise. Corpo masculino: a nudez como manifestação cultural na publicidade de moda. FDeportes.com. Ano 19, № 198. Buenos Aires.
} 
Comparando as duas capas de revista, fica clara a abordagem de diferentes etnias, principalmente, se for considerado o uso da indumentária como um enunciado de significações. No primeiro caso, as peças indicam um apelo elegante, pela formalidade que implica no uso de peças de alfaiataria. Já no segundo exemplo, o modelo com pele negra usa uma roupa casual, sem pretensões de representação do luxo e, pelo contrário, apresenta um visual jovem - pelo uso de jaqueta esportiva e calça jeans.

Mesmo com foco nas identidades não normativas, percebe-se que a comunicação ao público homossexual masculino também se apoia fortemente em sistemas já estabelecidos pela estrutura patriarcal. Ao invés da quebra da normatividade, que provavelmente se estruturaria em outro tipo de representação masculina, são lançados novos discursos que comprometem e reforçam questões aprisionadoras das identidades como a virilidade (BOURDIEU, 2014), etnia culturalmente dominante (BHABHA, 1998), condição de poder de consumo elevada.

Em contraponto, Regina Navarro Lins (2013) relata a matéria veiculada na rede CBS News $^{3}$ sobre a tentativa de combate aos estereótipos de gênero que acontece na Suécia. Ao mesmo tempo em que, uma pré-escola do distrito de Sodermalm, em Estocolmo, faz uso de uma pedagogia sexualmente neutra (LINS, 2013), as publicidades deste país também criam estratégias para o extermínio dos estereótipos de gênero.

Nesta concepção, a marca sueca de brinquedos infantis Top Toy abre as possibilidades de representação de gênero e desenvolve peças publicitárias nas quais os estereótipos identitários são quebrados. A empresa afirma não criar produtos para meninos ou meninas, mas, sim, para crianças (SEM preconceito, 2014), como pode ser percebido na imagem figura 4.

\footnotetext{
${ }^{3}$ Disponível em <HTTP://bitly/ischD6>, acesso em Agosto de 2014.
} 


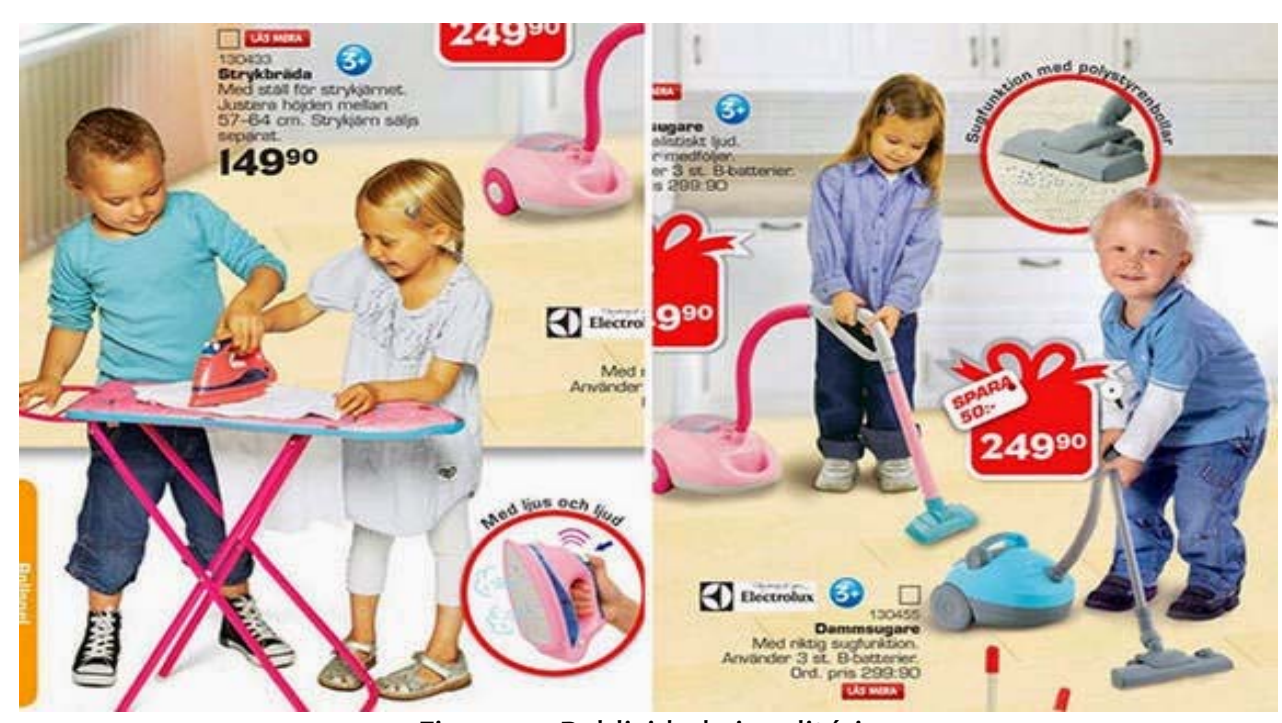

Figura 4 - Publicidade igualitária

Fonte: Site Na Pracinha, acesso em 05 de agosto de 2014.

Na imagem, os papéis normativos de masculino e feminino são quebrados através de situações nas quais se representam as tarefas estereotípicas pertencentes à mulher. Além disso, a criança que representa o papel feminino da imagem à direita de quem olha, está usando camisa e calça jeans - uma produção de vestuário que também ajuda a criar outras possibilidades de representação do gênero, fugindo da norma usual de meninas usando vestidos.

Da mesma forma que o consumo pode normatizar relações de gênero, McCraken (2013) reforça a função da construção cultural através da prática do consumo. Desta forma, o consumo também consegue estabelecer novas possibilidades representativas e, portanto, ampliar os conceitos de regulação do marco social.

Assim, o fato do mercado de consumo conseguir retratar novos formatos de aquisição simbólica além do padrão azul/rosa, é também uma oportunidade de criar discursos elucidativos sobre as identidades de gênero não normativas, flexibilizadas e fragmentadas. Para tanto, é necessário, primeiramente, que o mercado de consumo também esteja atento às novas possibilidades identitárias, que não as estereotipadas ou homogêneas. Com a retratação de representações não normativas, como a desenvolvida na Suécia, se criam legitimações de uma pluralidade mais abrangente de identidades, construindo uma nova cultura material, mais democrática e libertária. 


\section{Alteridade, quebra dos estereótipos e o gênero não binário}

Na medida em que o mercado de consumo possibilita a construção de uma identidade, ele dá origem a um sentimento ambivalente entre vivenciar uma identidade plenamente (aos que se adéquam à normatividade e são representados) e excluir quem não se adéqua às categorias hegemônicas.

Este conceito de ambiguidade é usado para tratar das características do contexto contemporâneo e se apoia na "verdade" para falar das ideologias aceitas ou das representações adequadas ao contexto social (BAUMAN, 1999). Neste caso, são verdadeiras e adequadas as identidades masculinas e femininas heterossexuais, influenciando nas práticas e representações das identidades sujeitadas.

A verdade é, em outras palavras, uma relação social (como poder, propriedade ou liberdade): aspecto de uma hierarquia feita de unidades de superioridade e inferioridade; mais precisamente, um aspecto da forma hegemônica de dominação ou de uma pretensão a dominar pela hegemonia (BAUMAN, 1999, p. 245-246).

O padrão hierárquico,, é estabelecido pelo que se entende como adequado e verdadeiro. As demais representações identitárias de gênero estariam localizadas na marginalidade e, por isso, seriam, discriminadas e negadas. Para que esta forma excludente de interpretação das identidades de gênero não binárias seja afastada da rotina contemporânea seria necessária a prática das relações de alteridade. Esta função acontece no sentido que as relações de alteridade implicam na construção identitária de um sujeito lançada para fora, ou seja, em direção ao que é externo, como uma forma de perceber-se no outro (BHABHA, 1998).

As relações de alteridade, portanto, produziriam oportunidades de entendimento e aceitação da diferença. Ao mesmo tempo em que a quebra dos estereótipos de gênero, promulgados também pelo consumo, conduzirá para uma interpretação da identidade não normativa e não mais se baseando em imagens pré-constituídas e imutáveis. 
Na mesma lógica de quebra do binarismo "colonizador/colonizado" proposta por Bhabha (1998), identidades híbridas, desconstruídas, mutáveis também constituem as relações de gênero - quebrando a normatividade "masculino/feminino" e abrindo espaço para as demais possibilidades intermediárias ou transitórias.

No entanto, se percebe que o consumo atua na exploração das etiquetas (BAUMAN, 2008) como forma de criar estereótipos e organizar, de alguma forma, o contexto social. Portanto, é fundamental que exista uma forma de consumo mais reflexiva e questionadora sobre qual é a simbologia aplicada a cada objeto - como atos simbólicos significantes (GEERTZ, 2003).

Por fim, se faz necessário que os meios de comunicação, de consumo e a cultura incorporem visões menos frias e imutáveis, aceitando a dinamicidade das identidades, possibilitando novas significações de gênero, menos arbitrárias ou estereotipadas. Este caminho tende a ser construído através das relações de alteridade, que implicam em um exercício de olhar o outro, não com uma função de criar categorias, mas sim de compreender as liberdades necessárias para sua a plenitude de vivência identitária.

\section{Referências}

ANA Amélia (Org.). OvoNovo[Blog da internet]. São Paulo, 2014. Disponível em <http://ovonovo.wordpress.com/2014/02/06/o-projeto-rosa-e-azul/\#>. Acesso em 05 de Agosto de 2014.

BOURDIEU, Pierre. A dominação masculina. Rio de Janeiro: Bestbolso, 2014.

BAUMAN, Zygmunt. Modernidade e ambivalencia. Rio de Janeiro: Zahar, 1999.

BAUMAN, Zygmunt. Vida para consumo: A transformação das pessoas em mercadoria. Rio de Janeiro: Zahar, 2008.

BHABHA, Hommi. O local da cultura. Belo Horizonte: UFMG, 1998. 
BUTLER, Judith. Cuerpos que importan: sobre los límites materiales y discursivos del "sexo". Buenos Aires, Barcelona, México: Paidós, 1993.

BUTLER, Judith.Problemas de gênero: feminismo e a subversão da identidade. Rio de Janeiro: Civilização Brasileira, 2008

FOUCAULT, Michel. Tecnologíasdelyo y otros textos afines. Barcelona: Paidós, 1988.

GEERZ, Clifford. A interpretação das culturas. São Paulo: LTC, 2003.

HALL. O sujeito pós moderno. Rio de Janeiro: DP\&A, 2006.

KOOK, Luca (Org.)Noise Maker.[Blog da internet]. Blumenau, 2009. Disponível em <http://www.noisemaker.com.br/2009_06_01_archive.html>. Acesso em 10 de abril de2015.

LINS, Regina Navarro. O livro do amor: vol. I. Rio de Janeiro: Best Seller, 2013.

MAGAZINE OBSESSION. Disponível em

<https://magazineobsesion.wordpress.com/2008/12/17/malvino-salvador-e-capa-darevista-dom-de-dezembro/>. Acesso em 10 de abril de 2015.

MCCRACKEN, Grant. Cultura \&consumo. Rio de Janeiro: MAUAD, 2013.

PELEGRINI, Flávia; BARRETO, Mimiriam (Org.). Na pracinha: vamos brincar lá fora. [Bloog da internet], 2014. Disponível em <www.napracinha.com.br >. Acesso em 05 de Agosto de 2014.

SEM preconceito: menino brinca de boneca em catálogo de brinquedos. O Globo, Rio Janeiro, 06 de dez. 2012. Caderno cultura / magazine. Disponível em <http://oglobo.globo.com/cultura/megazine/sem-preconceito-menino-brinca-de-bonecaem-catalogo-de-brinquedos-6951923\#ixzz3A6PsVMnU>. Acesso em Agosto de 2014.

Recebido em: 20/12/2014 Aprovado em: 11/05/2015

Universidade do Estado de Santa Catarina - UDESC Centro de Ciências Humanas e da Educação - FAED

Revista PerCursos Volume 16 - Número 30 - Ano 2015 revistapercursos@gmail.com 